\section{WORKFORCE COMPENSATION POLICIES FOR LEAD TEACHERS IN STATE-FUNDED PRESCHOOL}

\author{
ZAYNAB KHAN, \\ ALLISON FRIEDMAN-KRAUSS (FACULT ADVISOR)
}

\section{* ABSTRACT}

Each state in the US has different compensation parity policies for their early childhood education programs. Currently, public preschool teachers often have similar qualifications to K-3 teachers but earn significantly lower salaries. Compensation parity policies ensure that equivalent work and qualifications are compensated with equivalent pay and benefits. Using data collected by the National Institute of Early Education Research (NIEER), I organized and analyzed policy data from all state-funded preschool programs in the U.S., with a focus on state compensation parity policies for lead preschool teachers. Ultimately, my purpose was to understand state-funded preschool compensation parity for lead teachers in order to identify areas of improvement for the workforce within early education programs. I initially hypothesized that Pre-K programs that required pay parity did not cost states more per child than Pre-K programs that did not require pay parity. Literature from NIEER and other early education research institutions has shown that quality early education programs are critical in a child's formative years and suggests that a more satisfied workforce yields more positive outcomes for children. Parity policies in state-funded Pre-K programs are not highly correlated to spending per child or program quality. Moreover, parity policies improve workforce well-being and should still be incorporated into state-funded Pre-K. Results show that there are only six programs across four states that require full salary parity for lead preschool teachers and no states require benefit parity for lead preschool teachers in both public and private settings. No clear pattern has emerged between compensation parity policies and state preschool spending or program quality.

\section{INTRODUCTION \\ i. What is compensation parity?}

Many preschool teachers earn substantially less than their counterparts in K-3 despite having comparable education and training. ${ }^{[3]}$ A lack of parity in both salaries and benefits between preschool and K-3 teachers has important implications for both the teachers themselves as well as for the children they serve. In this study, I apply the Center for the Study of Child Care Employment's (CSCCE) definition of workforce compensation parity to analyze the workforce compensation parity policies in state-funded preschools in the U.S. ${ }^{[10]}$ According to CSCCE, pay parity occurs when preschool teachers and K-3 teachers with equal qualifications and work experience receive equal pay (TABLE 1).

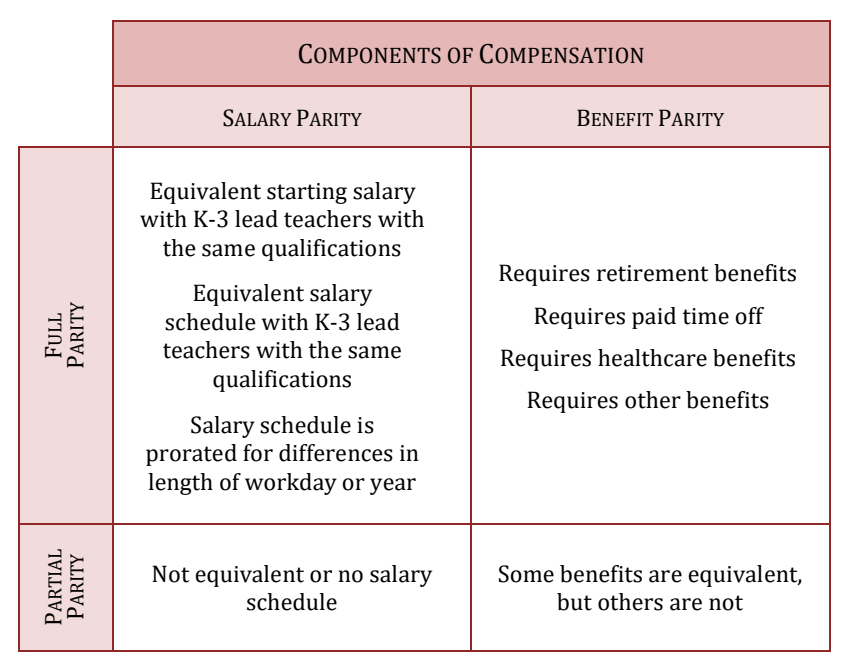

TABLE 1: Compensation Parity \& Related Forms of Compensation Improvement

NOTE. Definitions of parity as defined above.

SOURCE: Adapted from Whitebook, Marcy, and Caitlin McLean. "In Pursuit of Pre-K Parity." Center for the Study of Child Care Employment, Apr. 2017. 
TABLE 1 outlines how CSCCE defines compensation parity. This definition divides parity into multiple categories such as full parity, partial parity, sub parity, and alternative forms of compensation. Parity is equivalent compensation which includes:

1) starting salary,

2) salary schedule,

3) benefits, and

4) payment for professional responsibilities for employees with similar qualifications.

Full parity is when teachers receive equivalent treatment across all four parity categories. Partial parity is the equivalent treatment across some of the parity categories. For example, starting salary could be the same, while salary schedule, benefits, and/or payment for professional responsibilities may differ. ${ }^{[1]}$ Sub-parity is similar to partial parity but does not entail equivalent treatment across all four parity categories. Alternative forms of compensation include strategies to improve compensation but do not fall into one the three other categories. ${ }^{[1]}$ Only full and partial parity will be further discussed in this paper.

Early childhood education in the U.S. consists of a variety of programs such as the federal Head Start program, childcare, state-funded preschool, or private school. This paper will specifically discuss state-funded preschool. State-funded preschool is defined as a program that is directed, funded, and controlled by the state, serves mainly 3 and 4 year-olds, and focuses on early childhood education. ${ }^{[3]}$ Furthermore, state-funded preschool is a distinct program from state-subsidized childcare, programs that do not need to include early learning components. Some states such as New Jersey have multiple preschool programs which are all funded and instituted by the state. Each state is responsible for the licensing and administration of these programs. State-funded preschool programs may be provided in both public (e.g., public schools) and nonpublic settings (e.g., childcare centers) when states have mixed-delivery systems.

This paper will specifically focus on parity for lead teachers in state-funded Pre-K, in contrast to assistant teachers or other staff employed at state- funded preschool programs. Lead teachers are often required to have the similar qualifications to K-3 teachers (such as a bachelor's degree). Assistant teachers often do not need the same level of education as lead teachers and are typically not present in K-3 programs. Qualifications requirements for lead teachers can be compared to those of K-3 teachers as they require similar education levels.

\section{ii. Why is compensation parity important?}

Prior research suggests that teacher compensation affects both teachers as well as their students. ${ }^{[9]}$ For example, improved well-being of the preschool workforce is associated with higher quality preschool programs. One recent review found that teacher stress was associated with poor teacherchild relationships and ineffective teaching of social and emotional skills. ${ }^{[9]}$ Teachers' financial instability was identified as a significant source of stress and thus associated with less positive child outcomes. Low emotional wellness of teachers is associated with negative effects on students such as misbehavior, indicating the relationship between teacher wellness and student outcomes. ${ }^{[7]}$

Furthermore, low wages are correlated with high turnover rates. ${ }^{[9]}$ Consequently, this may negatively affect program quality for children. Parity policies in general are associated with higher wages for lead teachers and can improve teacher well-being. Compensation parity is critical because it is associated with higher wages for preschool teachers, putting them on a pay scale like their K-3 colleagues. While both K-3 and many preschool teachers are required to have the same educational backgrounds (e.g., at least a BA), preschool teachers typically earn significantly less than K-3 teachers. Teachers in the federal Head Start program with at least a BA still make, on average, $\$ 23,000$ less than public K-3 teachers. ${ }^{[2]}$

In a study conducted by the research institute Child Trends, researchers examined Alabama's First Class Pre-K program after the state increased funding for salary parity in 2016. ${ }^{[5]}$ Teachers began receiving pay similar to public K-3 teachers. In this qualitative study, some preschool directors reported 
that they could lead more effectively since parity resulted in easier recruitment of high-quality teachers. Furthermore, the researchers also noticed an increase in teamwork after the policy took effect. From the preschools the researchers surveyed, all directors reported high staff retention rates of teachers. More lead teachers opted to remain employed within Alabama's First Class Pre-K program than before, and directors and teachers noted that there was an increased amount of interest from public school teachers to find employment in Alabama's First Class Pre-K program. However, this did not apply to auxiliary staff, who were not affected by the new parity policy. Teachers also reported better economic and personal well-being after salary parity went into effect. ${ }^{[5]}$ While this study was conducted in 2016, the parity policies remain in place in Alabama's First Class Pre-K. ${ }^{[8]}$

Taken together, this research by Child Trends and the paper Early Care and Education Teacher Well-Being: Associations with Children's Experience, Outcomes, and Workplace Conditions: A Research-to-Policy Brief suggests that compensation parity is an essential ingredient for improving preschool program quality. As a result, it can potentially improve outcomes for children in their formative years and teachers' well-being. Further, this research highlights that it is important for states to prioritize compensation parity policies in their state-funded preschool programs and that it is necessary to understand the landscape of compensation parity policies in state-funded preschool.

iii. What are the main questions relating to the state of compensation policies in statefunded preschool?

In response to the existing literature that indicates the importance of the compensation parity policies, I examined the existing structure of parity policies within state-funded Pre-K. In this exploratory paper, I addressed the following questions:

1) What do we know about preschool parity policies?

2) Which state-funded preschool programs institute partial or full parity for lead teachers?
3) How do parity policies differ across public and nonpublic settings within state-funded preschool programs?

4) How are parity policies related to teacher salaries for public programs?

5) To what extent do parity policies relate to state preschool spending and program costs?

6) To what extent do parity policies relate to the quality of state-funded preschool programs?

Ultimately, this research focuses on pay parity policies within the different state-funded preschool programs across the United States and their relationship to cost and compensation in Pre-K. This research was conducted to understand if programs with pay parity policies spent more per child and if programs with pay parity policies had a higher wage for teachers.

\section{Methodology}

The National Institute for Early Education Research (NIEER) has tracked state-funded preschool enrollment, spending, and policies in order to support quality programs across states since 2002. Recently, NIEER has taken an in-depth look into compensation parity policies, including the extent to which they support the preschool teaching workforce. Data used in this paper pertain to the 2017 2018 school year.

NIEER surveys all 50 states, the District of Columbia, and U.S. territories about their current policies regarding their state-funded preschools. All states that have state-funded preschool programs have provided requested data. This includes 61 preschool programs across 44 states and D.C.; the programs serve over 1 million children. This information is compiled into the annual State of Preschool Yearbook. ${ }^{[3]}$

To explore lead preschool teacher compensation parity policies, I used data about state-funded preschool policies, such as each state's required teacher qualifications, average salary of lead preschool teachers, and average salary of lead K-3 teachers, for programs in both public and nonpublic settings. That is, although all programs receive state funding, many states use a mixed-delivery system where some preschool programs operate in public 
schools and others operate in nonpublic settings such as private childcare centers or Head Start programs. While data were collected on the 44 states, D.C., and territories (only Guam) that have a state-funded preschool program, only the states and D.C. were included in the analyses for this study. ${ }^{[a]}$

Quality as discussed throughout the paper refers to the NIEER's quality standards, which evaluate programs according to 10 benchmarks: early learning and development standards, curriculum support, teacher and assistant teacher educational background, training, and professional development, class sizes, staff-student ratios, and continuous quality improvement system.

I conducted a thorough literature review of NIEER's previous publications on compensation parity as well as other credible publications to understand compensation parity policies and their importance. To analyze the current state of compensation parity for lead teachers in state-funded preschool programs, I analyzed raw survey data collected by NIEER for the 2017-2018 State of Preschool Yearbook. I also conducted statistical analyses, including correlations and regression analyses, on NIEER's data to explore associations between compensation parity policies, state preschool spending, and preschool quality.

For the regression analysis between parity policies and state preschool spending, the length of the day was included as an independent variable in the regression. The dependent variable, adjusted spending per child in each state's Pre-K program, was regressed against the following binary variables: if they program offered part day, full day, or extended day service and whether the program offered partial salary parity, full salary parity, and benefit parity within their programs.

A regression analysis was also conducted between parity and quality benchmarks. Given that prior literature finds an association between teacher compensation and preschool quality, I also explored the association between state preschool programs' parity policies and NIEER's 10 benchmarks for preschool quality. ${ }^{[6]}$ Examples of NIEER's quality stand- ard benchmarks include supports for curriculum implementation, qualifications of lead (at least a B.A.) and assistant teachers (at least a Child Development Associate (CDA)), class size (maximum 20 children) and staff to teacher ratios (1:10 or better), as well as other non-workforce related specifications (such as required health screenings for children). All the programs are graded on quality on a scale from 1-10. The programs are evaluated across the 10 policy standards and then given an average total score.

\section{RESULTS \& DISCUSSION \\ i. What do we know about preschool parity policies? \\ Of the 44 states and District of Columbia} that offered state funded preschool, some states required similar qualifications for lead preschool teachers and public-school K-3 teachers. According to NIEER's 2018 Workforce Special Report, 28 states required that all lead teachers in state-funded preschool have at least a bachelor's degree (B.A.). 25 states required that lead teachers have an additional state-specified certification. However, of those states that require both a B.A. and a certification, only four -Hawaii, New Jersey, Oklahoma, and Rhode Island -require starting salary parity. ${ }^{[3]}$

ii. Which state-funded preschool programs institute partial or full parity for lead teachers? I explored state preschool parity policies to determine which states have full and partial parity policies in place for lead preschool teachers. NIEER collected data on state policies regarding both salary parity and benefit parity in state-funded preschool. As per the data from the 2017-2018 State of Preschool Yearbook, there were no states that required both salary and benefit parity for all lead teachers in state-funded preschool programs, which includes teachers in programs that offer both nonpublic and public settings.

Fifteen state-funded preschool programs have policies in place that meet the requirement for at least one component of salary parity, such as equivalent starting salaries but not an equivalent sal-

\footnotetext{
${ }^{[a]}$ Consistent with U.S. government statistical reporting practices, the District of Columbia will be referred to as a "state" throughout this report. Hence, we report 45 "states" providing state-funded preschools.
} 


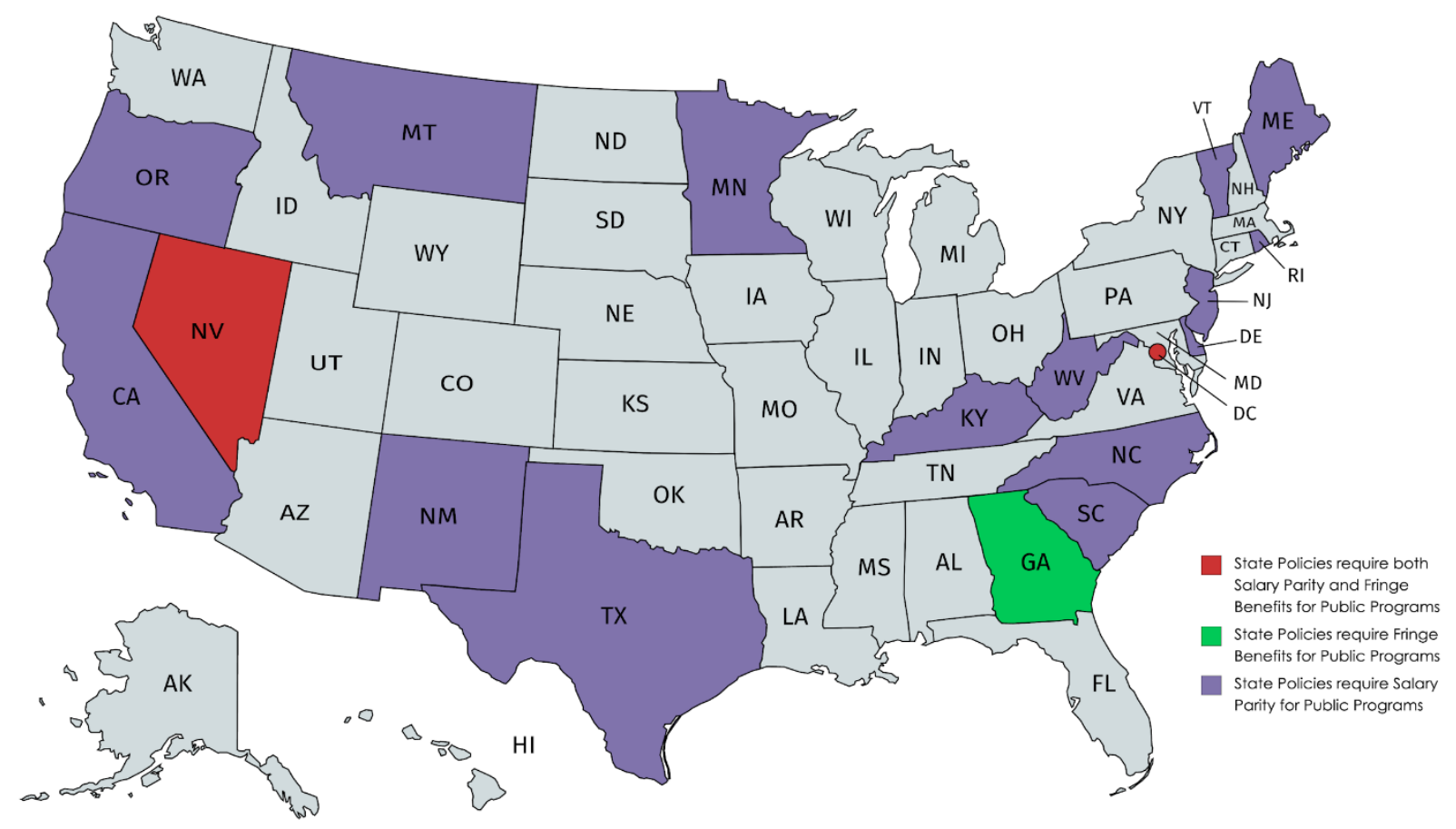

FIGURE 1: Map of Salary and Benefit Parity Policies for Lead Teachers in State-Funded Preschool Programs Employed by Public Schools Compared to K-3 Lead Teachers

Note: Map outlining parity by state public programs.

ary schedule. However, there are only six statefunded preschool programs that require full salary parity, which requires all three components (equivalent starting salary, equivalent salary schedule, and proration of salary based on work hours, see TABLE 1) for lead teachers in both public and nonpublic programs. These six programs are in four states: California, Minnesota, New Jersey, and Oregon. Only six programs meet at least one component of benefit parity, while no state program meets all three categories of benefit parity (see TABLE 1) for teachers in all settings.

iii. How do parity policies vary across public and non-public settings?

In many state-funded preschool programs, parity policies differ for preschool teachers employed by public and non-public schools. Parity policies are more likely to be in place for preschool teachers employed by public rather than non-public schools. According to the NIEER Workforce Special Report, "In states requiring the same degree requirements for all teachers, almost 70\% (of those with data) reported wage disparities where preschool public school teachers earned up to $\$ 21,136$ more than private preschool teachers in the same program. Disparities are even larger when comparing state-funded preschool teachers where a bachelor's degree is required to public school K-3 teachers. Preschool pay gaps of $\$ 20,000$ to $\$ 30,000$ per year are common. ${ }^{\prime[3]}$

Moreover, there are 19 state-funded preschool programs that require full salary parity only for teachers employed by public programs. Oregon, California, New Mexico, Texas, Kentucky, Minnesota, West Virginia, North Carolina, South Carolina, New Jersey, Delaware, Rhode Island, Vermont, and Maine have some form of salary parity. Only three states (Nevada, D.C., and Georgia) require full benefit parity for lead preschool teachers employed by 
public schools. Of these, only the District of Columbia and Nevada require both salary and benefit parity for state-funded preschool teachers employed by public schools.

iv. How are parity policies related to teacher salaries for public programs?

One result of the lack of parity policies in state-funded preschool programs is that preschool lead teachers in public programs with similar qualifications as public K-3 teachers often receive significantly less pay for similar work. According to the 2017-2018 Yearbook data, among the states that reported preschool teacher salary, state-funded preschool teachers employed by public schools earned $\$ 7,456$ less on average than public elementary school teachers. This gap is even larger when comparing lead state-funded preschool teachers employed by nonpublic settings with K-3 teachers; on average, this gap is $\$ 17,729 .{ }^{[3]}$

I also explored the extent to which salary parity policies in state-funded preschool were related to lead preschool teacher salaries. However, only 30 states provided data on average salaries for lead preschool teachers. When examining the states that require full salary parity for all programs, there still exists a significant wage gap between preschool teachers and K-3 teachers. For example, in California's Transitional Kindergarten (TK), a preschool program that serves 4-year-olds, the wage gap is $\$ 18,126$ despite TK being considered an early year of kindergarten by California. ${ }^{[b]}$ Similarly, in Oregon's Preschool Promise program, the wage gap is $\$ 15,413$. Both programs institute salary parity, yet there still exists a large discrepancy in wages. ${ }^{[3]}$

The inconsistency of parity policies and teacher salaries across the different programs can be partly attributed to the split between public and nonpublic program designations. For example, New Mexico institutes full salary parity for preschool teachers in public schools but not those teaching in private settings (though still part of the state-funded program). The wage gap between state-funded, public school lead preschool and K-3 teachers in New Mexico is only $\$ 2,745$. Conversely, in Arkansas, where there are no salary parity policies, the wage gap between public lead preschool teachers and public $\mathrm{K}-3$ teachers is $\$ 8,824$. Even after adjusting for cost of living, the wage gap in Arkansas is significantly higher than the wage gap in New Mexico. ${ }^{[3]}$

v. To what extent do parity policies relate to state spending and program costs?

A regression analysis showed a statistically insignificant correlation between salary parity policies and state spending per child for preschool. As an example, Nevada and the District of Columbia are the only two states that have parity policies for both salary and benefits for lead preschool teachers employed in public settings (see TABlE 2). Yet the state spending per child is significantly different in these two states. The District of Columbia spends $\$ 17,545$ per child, which is the most compared to any other state program. The state of Nevada spends $\$ 4,025$ per child (which is only slightly lower than the median of $\$ 4,769$ per child). When adjusted for cost of living, Nevada spends $\$ 4,124$ per child and the District of Columbia spends $\$ 15,008$. Nevada still institutes full compensation parity for public programs despite spending significantly less than the only other state that institutes full parity policies for both salary and benefits. However, it is worth noting that Nevada's programs are part-day and only serve students for 2.5 hours a day while the District of Columbia's program serves students for 6.5 hours a day (as indicated in TABLE 2).

TABLE 3 indicates that it is somewhat surprising that there is only a weak but nonsignificant correlation between spending per child and parity policies. This is likely due to other variables such as differing operating times (as in the example of District of Columbia and Nevada). That is, some programs are full-day while others are half-day, which affect costs. Programs also vary in the total number of hours and/or days per year, which also affects costs. Shorter programs will cost significantly less than programs that serve students for longer periods of time. Results of the regression analysis indicated only a weak and nonsignificant correlation between pay parity policies and the spending per child of each

\footnotetext{
${ }^{[b]}$ While the state of California considers TK a kindergarten program, it meets NIEER's definition of a state-funded preschool program ${ }^{[3]}$. Despite TK being viewed as kindergarten by CA, there is still a large salary gap between preschool teachers in TK and elementary school teachers.
} 


\begin{tabular}{|c|c|c|c|c|c|c|}
\hline Program & & $\begin{array}{l}\text { Justed } \\
\text { ding per } \\
\text { child }\end{array}$ & Operating Schedule & $\begin{array}{l}\text { Has at least partial } \\
\text { salary parity in } \\
\text { public programs }\end{array}$ & $\begin{array}{c}\text { Has full salary } \\
\text { parity for public } \\
\text { programs }\end{array}$ & $\begin{array}{c}\text { Has full benefit } \\
\text { parity for public } \\
\text { program }\end{array}$ \\
\hline New Jersey Abbott & $\$$ & 16,453 & Full Day & $\mathrm{x}$ & $\mathrm{x}$ & \\
\hline District of Columbia & $\$$ & 15,008 & Extended Day & $x$ & $x$ & $x$ \\
\hline Oregon Preschool Promise & $\$$ & 11,899 & Determined Locally & $\mathrm{x}$ & $\mathrm{x}$ & \\
\hline California TK & $\$$ & 10,246 & Part Day & $\mathrm{x}$ & $\mathrm{x}$ & \\
\hline Alaska & $\$$ & 9,731 & Determined Locally & $x$ & & \\
\hline Pennsylvania K4 \& SBPK & $\$$ & 9,289 & Part Day & & & \\
\hline Wisconsin HdSt & $\$$ & 9,231 & Part Day & & & \\
\hline Oregon HdSt & $\$$ & 9,203 & Part Day & & & \\
\hline Montana & $\$$ & 8,892 & Full Day & $x$ & $\mathrm{x}$ & \\
\hline Connecticut CDCC & $\$$ & 8,341 & Extended Day & & & \\
\hline Washington & $\$$ & 8,321 & Part Day & & & \\
\hline Minnesota HdSt & $\$$ & 8,312 & Determined Locally & & & \\
\hline Connecticut Smart Start & $\$$ & 8,046 & Full Day & & & \\
\hline Pennsylvania RTL & $\$$ & 8,041 & Part Day & & & \\
\hline California SPP & $\$$ & 7,704 & Part Day & & & \\
\hline West Virginia & $\$$ & 7,481 & Full Day & $\mathrm{x}$ & $\mathrm{x}$ & \\
\hline Delaware & $\$$ & 7,270 & Part Day & $\mathrm{x}$ & $\mathrm{x}$ & \\
\hline Michigan & $\$$ & 7,026 & Part Day & & & \\
\hline Connecticut SR & $\$$ & 6,658 & Part Day & & & \\
\hline Vermont & $\$$ & 6,460 & Part Day & $x$ & $x$ & \\
\hline Arkansas & $\$$ & 6,392 & Extended Day & & & \\
\hline New Mexico & $\$$ & 6,265 & Part Day & $x$ & $x$ & \\
\hline New Jersey ECPA & $\$$ & 6,111 & Part Day & $\mathrm{x}$ & $\mathrm{x}$ & \\
\hline North Carolina & $\$$ & 5,945 & Extended Day & $\mathrm{x}$ & $\mathrm{x}$ & \\
\hline Hawaii & $\$$ & 5,877 & Determined Locally & $x$ & & \\
\hline Rhode Island & $\$$ & 5,860 & Full Day & $\mathrm{x}$ & $x$ & \\
\hline New York & $\$$ & 5,659 & Part Day & & & \\
\hline Minnesota VPK & $\$$ & 5,657 & Part Day & $x$ & $\mathrm{x}$ & \\
\hline Alabama & $\$$ & 5,566 & Extended Day & $\mathrm{x}$ & & \\
\hline Kentucky & $\$$ & 5,135 & Part Day & $\mathrm{x}$ & $x$ & \\
\hline Tennessee & $\$$ & 5,127 & Full Day & $\mathrm{x}$ & & \\
\hline Missouri & $\$$ & 5,090 & Part Day & $\mathrm{x}$ & & \\
\hline Georgia & $\$$ & 4,769 & Extended Day & $\mathrm{x}$ & & $x$ \\
\hline Louisiana NSECD & $\$$ & 4,733 & Full Day & & & \\
\hline Illinois & $\$$ & 4,676 & Part Day & & & \\
\hline Ohio & $\$$ & 4,501 & Part Day & & & \\
\hline lowa Shared Visions & $\$$ & 4,404 & Determined Locally & $\mathrm{x}$ & & \\
\hline Louisiana LA 4 & $\$$ & 4,304 & Full Day & & & \\
\hline Arizona & $\$$ & 4,205 & Part Day & & & \\
\hline Nevada & $\$$ & 4,124 & Part Day & $\mathrm{x}$ & $x$ & $\mathrm{x}$ \\
\hline Pennsylvania HSSAP & $\$$ & 4,122 & Part Day & & & \\
\hline Oklahoma & $\$$ & 4,094 & Part Day & $x$ & & \\
\hline Virginia & $\$$ & 3,768 & Part Day & $\mathrm{x}$ & & \\
\hline Louisiana $8(\mathrm{~g})$ & $\$$ & 3,747 & Full Day & & & \\
\hline Pennsylvania Pre-K Counts & $\$$ & 3,737 & Part Day & & & \\
\hline Texas & $\$$ & 3,669 & Part Day & $\mathrm{x}$ & $\mathrm{x}$ & \\
\hline Maryland & $\$$ & 3,622 & Part Day & & & \\
\hline Wisconsin $4 \mathrm{~K}$ & $\$$ & 3,550 & Part Day & & & \\
\hline Maine & $\$$ & 3,476 & Part Day & $\mathrm{x}$ & $\mathrm{x}$ & \\
\hline New Jersey ELLI & $\$$ & 3,470 & Part Day & $\mathrm{x}$ & $x$ & \\
\hline South Carolina & $\$$ & 3,118 & Extended Day & $\mathrm{x}$ & $\mathrm{x}$ & \\
\hline lowa SWVPP & $\$$ & 2,936 & Part Day & $x$ & & \\
\hline Massachusetts UPK & $\$$ & 2,731 & Determined Locally & & & \\
\hline Mississippi & $\$$ & 2,522 & Full Day & & & \\
\hline Colorado & $\$$ & 2,457 & Part Day & & & \\
\hline Florida & $\$$ & 2,241 & Determined Locally & & & \\
\hline Nebraska & $\$$ & 1,986 & Part Day & & & \\
\hline Kansas Preschool Pilot & $\$$ & 1,803 & Part Day & & & \\
\hline Massachusetts Ch7 & $\$$ & 845 & Determined Locally & & & \\
\hline North Dakota & $\$$ & 612 & Determined Locally & & & \\
\hline Kansas State Pre-K 4 Year Old At-Risk Program & $\$$ & 550 & Part Day & & & \\
\hline
\end{tabular}

TABLE 2: State Preschool Spending Per Child, Minimum Operating Schedule, and Parity Policies ${ }^{[c]}$

NOTE. This table represents data available on the operating schedule, spending per child, partial and full salary parity, and full benefit parity.

${ }^{[c]}$ Full day programs serve students for at least 5.5 hours a day. Extended day programs serve students for more than 6.5 hours a day. Part day programs serve students for at least 3 hours a day but not more than 5.5 hours. 


\begin{tabular}{|l|c|c|c|}
\cline { 2 - 4 } \multicolumn{1}{c|}{} & \multicolumn{2}{c|}{ (SE) } & $p$ \\
\hline Part-Day Program (n=35) & -375.9859 & 1165.289 & $\mathrm{P}>.05$ \\
\hline Full-Day Program (n=10) & 949.3526 & 1428.907 & $\mathrm{P}>.05$ \\
\hline Extended-Day Program (n=7) & 857.1525 & 1640.042 & $\mathrm{P}>.05$ \\
\hline Partial Salary Parity (n=29) & -113.4493 & 1137.561 & $\mathrm{P}>.05$ \\
\hline Full Salary Parity (n=19) & 2041.8102 & 1223.313 & $\mathrm{P}>.05$ \\
\hline Full Benefit Parity (n=3) & 1266.2790 & 1996.638 & $\mathrm{P}>.05$ \\
\hline
\end{tabular}

TABLE 3: Regression analysis predicting Spending per Child from Teacher Salary Parity

\begin{tabular}{|l|c|c|c|}
\cline { 2 - 4 } \multicolumn{1}{c|}{} & \multicolumn{1}{c|}{ (SE) } & $p$ \\
\hline Part-Day Program (n=35) & 1.5262705 & 0.7695571 & $\mathrm{P}<.05$ \\
\hline Full-Day Program (n=10) & 2.8829284 & 0.9436502 & $\mathrm{P}<.01$ \\
\hline Extended-Day Program (n=7) & 2.3051779 & 1.0830838 & $\mathrm{P}<.05$ \\
\hline Partial Salary Parity (n=29) & 1.4399083 & 0.7512457 & $\mathrm{P}>.05$ \\
\hline Full Salary Parity (n=19) & -0.9485807 & 0.8078760 & $\mathrm{P}>.05$ \\
\hline Full Benefit Parity (n=3) & -1.7629463 & 1.3185800 & $\mathrm{P}>.05$ \\
\hline
\end{tabular}

TABLE 4: Regression Analysis predicting Quality Standard Benchmarks from Teacher Salary Parity 
state program $(p>.05)$. There are several limitations regarding finding a relationship between parity policies and state spending. Many states have varied operating schedules. While the analysis accounted for operating schedule, it did not account for how many calendar days children are served. Furthermore, class size, which varies amongst programs and is often a driver for program costs, was not controlled for.

\section{vi. How does parity relate to the quality of programs? \\ Results of the regression analysis from TABLE 4} indicated only a weak and nonsignificant correlation between pay parity policies and the number of quality standard benchmarks met by each state preschool program $(p>.05)$. In 2018, the programs that met every minimum quality benchmark were in Michigan, Alabama, and Rhode Island. NIEER does not include parity as one of their ten quality benchmarks and does not guarantee quality. None of these states institute full parity for their lead preschool teachers. However, both Rhode Island and Alabama required partial salary parity in their programs. The results suggest that there is no direct link between policies related to quality and parity policies. ${ }^{[3]}$ However, it is possible that preschool program quality is affected by consequences of parity such as high turnover rates. Similar to state spending, there are limitations regarding the relationship between quality and parity policies. While the literature suggested a relationship between parity and teacher well-being (and consequently quality), there are several factors not included in the analysis that could explain the weak correlation. The quality standards benchmarks represent policies related to quality but do not represent actual program quality. Further, the benchmarks include markers of quality that do not relate to the lead teachers at all such as a policy requiring that children receive health screenings.

\section{SUMMARY \& CONCLUSION}

In conclusion, compensation parity policies are policies that require preschool teachers to receive equal compensation, including both salary and benefits, on par with similarly qualified K-3 teachers. In general, parity policies should be associated with higher wages. However, results of this analysis indicate that few states institute parity policies in statefunded preschool. Teachers employed by public schools are more likely to be supported by parity policies in comparison to preschool teachers employed by nonpublic settings.

Moreover, there seems to be little correlation between state preschool spending per child and parity policies, but some evidence that a smaller wage gap between public preschool and public K-3 was associated with preschool programs having parity policies. In addition, qualitative studies indicate that parity policies improve teacher well-being which can improve program quality of state-funded programs. However, I found no direct link between program quality and enforced parity policies.

This study is a first step in understanding state-funded preschool compensation parity for lead teachers. Results indicate that most statefunded preschool programs have a long way to go to ensure that preschool teachers receive compensation packages on par with their K-3 counterparts. Future research could explore barriers that contribute to these discrepancies. Governments can create labor policies, such as parity and starting salaries, for their own workforce and therefore for teachers in public settings. However, it likely would be seen as government overreach for states to regulate work-

RESULTS INDICATE THAT MOST STATE-FUNDED PRESCHOOL PROGRAMS HAVE A LONG WAY TO GO TO ENSURE THAT PRESCHOOL TEACHERS RECEIVE COMPENSATION PACKAGES ON PAR WITH THEIR K-3 COUNTERPARTS. 
force policies for privately-run (non-public) programs even if they receive state funding. ${ }^{[1]}$ Furthermore, many states will delegate the implementation of parity policies to municipalities. Some local governments will require parity policies in their districts while others will not, resulting in different parity policies and varying wages across a state. Indeed, for many preschool programs that did not have compensation parity policies, these policies were determined at the local level by school districts. Additionally, as more state-funded preschool programs implement parity policies, future research could explore how changes in parity policies over time affect teacher salaries and turnover as well as preschool quality, spending, and child outcomes. Current budgeting deficits due to COVID-19 pandemic may result in the regression of parity policies, though so far this is not evident. ${ }^{[4]}$ While backtracking on parity policies is not a desirable outcome, it may serve as an opportunity to research the effects of compensation parity on teacher well-being, program quality, and child outcomes. Ensuring that the preschool workforce is well-compensated will be crucial to ensure that preschool programs have positive effects on young children's development, as well as for teachers' own well-being

\section{ACKNOWLEDGEMENTS}

I would like to thank Dr. Allison FriedmanKrauss as well as the National Institute of Early Childhood Education Research for their support in this project.

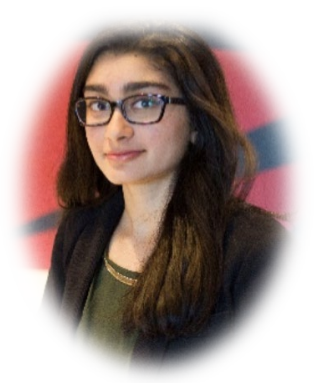

Zaynab Khan is a graduate from the Class of 2021. She majored in Mathematics and minored in Political Science and Economics. She was an Honors College student as well as a member of the Douglass Residential College community. As part of the Aresty Research Assistant Program, she worked with the National Institute of Early Education Research at the Rutgers Graduate School of Education to conduct research on early education policy, specifically on workforce compensation for early education teachers. She hopes to eventually pursue higher education in economics and conduct further policy related research.

\section{REFERENCES}

[1] Barnett, W. S. \& Kasmin, R. (2017). Teacher Compensation Parity Policies and State-Funded Pre-K Programs. New Brunswick, NJ: the National Institute for Early Education Research and Berkeley, CA: Center for the Study of Child Care Employment, University of California, Berkeley

[2] Barnett, W. S., Friedman-Krauss, A., Weisenfeld, G., Horowitz, M., Kasmin, R., \& Squires, J. H. (2017, May). The State of Preschool 2016.

HTTP://NIEER.ORG/WP-CONTENT/UPLOADS/2017/09/FULL_STATE_OF_PRESCHOOL_2016_9.15.17_COMPRESSED.PDF

[3] Friedman-Krauss, A., Barnett, S., Garver, K., Hodges, K., Weisenfeld, G., \& DiCrecchio, N. (2019, April). The State of Preschool 2018.

HTTP://NIEER.ORG/WP-CONTENT/UPLOADS/2019/08/YB2018_FULL-RE. PORTR3WAPPENDICES.PDF

[4] Friedman-Krauss, A., Barnett, S., Garver, K., Hodges, K., Weisenfeld, G., \& Gardiner, B. (2021, August). The State of Preschool 2020.

HTTPS://NIEER.ORG/WP-CONTENT/UPLOADS/2021/08/YB2020_FULL_REPORT_080521.PDF

[5] Gebhart, T., Carlson, J., Harris, P., \& Epstein, D. (2020 June). Workforce Perceptions and Experiences with the Alabama Early Care and Education Salary Parity Policy. Childtrends.org

[6] Jennings, P. A. (2014). Early Childhood Teachers' Well-Being, Mindfulness, and Self-Compassion in Relation to Classroom Quality and Attitudes Towards Challenging Students.

[7] Jennings, P., \& Greenberg, M. (2009). The Prosocial Classroom: Teacher Social and Emotional Competence in Relation to Student and Classroom Outcomes. Review of Educational Research, 79(1), 491-525. Retrieved May 18, 2021, from HTTP://WWW.JSTOR.ORG/STABLE/40071173

[8] Office of the Governor of Alabama. (2021, May 18). Governor Ivey Announces New First Class Pre-K Classrooms in First Round of Funding. Office of the Alabama Governor. HTTPS://GOVERNOR.ALABAMA.GOV/NEWSROOM/2021/05/GOVERNOR-IVEYANNOUNCES-NEW-FIRST-CLASS-PRE-K-CLASSROOMS-IN-FIRST-ROUND-OFFUNDING/

[9] Smith, S., \& Lawrence, S. (2019, March). Early Care and Education Teacher Well-Being: Associations with Children's Experience, Outcomes, and Workplace Conditions: A Research-to-Policy Brief (Rep.). (ERIC Document Reproduction Service No. ED597580)

[10] Whitebook, M. \&McLean, C. (2017). In Pursuit of Pre-K Parity: A Proposed Framework for Understanding and Advancing Policy and Practice. Berkeley, CA: Center for the Study of Child Care Employment, University of California, Berkeley and New Brunswick, NJ: the National Institute for Early Education Research. 